\title{
BIODIGESTÃo ANAERÓBIA DOS RESÍDUOS DA PRODUÇÃo AVÍCOLA: CAMA DE FRANGOS E CARCAÇAS
}

\section{MARCO A. P. ORRICO JÚNIOR ${ }^{1}$, ANA C. A. ORRICO ${ }^{2}$, JORGE DE LUCAS JÚNIOR ${ }^{3}$}

RESUMO: O propósito deste trabalho foi avaliar a produção de biogás, bem como os potenciais de produção e a qualidade do biofertilizante obtido com a biodigestão anaeróbia dos resíduos cama de frangos e carcaças de aves pré-compostados. Para tanto, foram pré-compostados cama de frango e carcaças de aves mortas em uma composteira durante um período de 60 dias, período necessário para que ocorresse decomposição prévia das carcaças e assim fosse possível manipular o material para abastecer os biodigestores. Após este período, o material foi utilizado para abastecer os biodigestores batelada de campo com capacidade de 60 litros de material em fermentação. Para o processo de biodigestão anaeróbia, foram efetuadas análises dos teores de sólidos totais (ST), sólidos voláteis (SV), composição química do efluente, potenciais de produção, além do número mais provável (NMP) de coliformes totais e termotolerantes no afluente e efluente. Os potenciais médios de produção de biogás foram: 0,$073 ; 0,152$ e $0,141 \mathrm{~m}^{3} \cdot \mathrm{kg}^{-1}$ de material, SV e ST adicionados, respectivamente. Foram observadas reduções acima de 99\% no NMP de coliformes totais e termotolerantes, sendo observado NMP de $3,7 \times 10^{5} \mathrm{~g}^{-1}$ no início e $7,45 \times 10^{2} \mathrm{~g}^{-1}$ no final.

PALAVRAS CHAVE: metano, dejeto, meio ambiente.

\section{ANAEROBIC DIGESTION OF WASTE FROM POULTRY PRODUCTION: POULTRY LITTER AND CARCASS}

\begin{abstract}
The purpose of this study was to evaluate the production of biogas, and the production potential, and quality of biofertilizer obtained from the anaerobic digestion of waste poultry litter and poultry carcasses pre composted. For this were pre composted poultry litter and carcasses of dead birds in a composter for a period of 60 days, time needed to occur prior decomposition of the carcasses and so it can manipulate the material to supply the biodigestor. After this period the material was used to supply the batch field biodigestor with a capacity of 60 liters of material in fermentation. For the process of anaerobic digestion tests were performed in the levels of total solids (TS), volatile solids (VS), chemical composition of effluent, and the most probable number (MPN) of total and thermotolerant coliforms in the influent and effluent. The potential average productions of biogas are: $0073,0152,0141 \mathrm{~m}^{3} \cdot \mathrm{kg}^{-1}$ of material, VS and TS added, respectively. There were reductions of over $99 \%$ in NMP of total and thermotolerant coliforms, and observed MPN of $3.7 \times 10^{5} \cdot \mathrm{g}^{-1}$ at the beginning and $7.45 \times 10^{2} \mathrm{~g}^{-1}$ at the end.
\end{abstract}

KEYWORDS: methane, waste, environment.

\section{INTRODUÇÃO}

A avicultura de corte brasileira produziu, durante o ano de 2007, cerca de oito milhões de toneladas de carne, o que corresponde a $16,4 \%$ da produção mundial. Com isso, as exportações atingiram 1,8 milhão de toneladas, aumentando a participação do Brasil para quase um terço do total do comércio exterior, com destaque para a quantidade de cortes embarcados. $\mathrm{O}$ consumo de $35,1 \mathrm{~kg}$ de carne de frango por habitante por ano está entre os mais elevados, observado nos países desenvolvidos (ANUALPEC, 2007).

\footnotetext{
${ }^{1}$ Doutorando em Zootecnia, Faculdade de Ciências Agrárias e Veterinárias, UNESP, Jaboticabal - SP, marcoorrico@ yahoo.com.br.

${ }^{2}$ Profa. Adjunta, Faculdade de Ciências Agrárias, UFGD, Dourados - MS, anaorrico@ufgd.edu.br.

${ }^{3}$ Prof. Titular, Faculdade de Ciências Agrárias e Veterinárias, UNESP, Jaboticabal - SP, jlucas@ fcav.unesp.br.

Recebido pelo Conselho Editorial em: 3-4-2009

Aprovado pelo Conselho Editorial em: 3-2-2010
} 
Como nas demais atividades agropecuárias, a avicultura de corte gera uma quantidade muito grande de resíduos (cama de frangos e aves mortas) que, se bem manejados, poderão tornar-se não apenas uma importante fonte de renda e agregação de valor à atividade, mas também um modelo de produção sustentável que vem tornando-se cada vez mais uma exigência de mercado. Para tanto, é necessário que haja a adoção de um sistema de tratamento desses resíduos a fim de evitar possíveis contaminações do ambiente (GÜNGÖR-DEMIRCI \& DEMIRER, 2004; ANGONESE et al., 2006).

A biodigestão anaeróbia é um sistema de tratamento no qual a matéria orgânica é degradada até a forma de metano $\left(\mathrm{CH}_{4}\right)$ e dióxido de carbono $\left(\mathrm{CO}_{2}\right)$ em condições anaeróbias (DEMIRER \& CHEN, 2005). O metano produzido pode ser utilizado como fonte de energia, na substituição de combustíveis fósseis e, deste modo, agrega valor à produção e diminui a emissão de dióxido de carbono (SILVA et al., 2005; ORRICO et al., 2007; SANTOS et al., 2007). As vantagens do processo são: redução de microrganismos patogênicos e odores, ocupa pequeno espaço físico para o tratamento dos resíduos, e a liberação de gases ou efluentes, resultantes do processo são facilmente controlados. Nos processos anaeróbios, ou nos sistemas de biodigestão anaeróbia, a degradação da matéria orgânica envolve a atuação de microrganismos procarióticos anaeróbios facultativos e obrigatórios, cujas espécies pertencem ao grupo de bactérias hidrolítico-fermentativas, acetogênicas produtoras de hidrogênio e arqueas metanogênicas (CÔTÉ et al., 2006; ALVAREZ et al., 2006).

SALMINEN \& RINTALA (2002) realizaram levantamento sobre os potenciais de geração de metano a partir dos resíduos de abatedouros e da criação de aves e ressaltaram a importância do aproveitamento desses resíduos com potenciais de: $0,20-0,25 \mathrm{~m}^{3}$ de $\mathrm{CH}_{4} \cdot \mathrm{kg}^{-1}$ de carcaça de aves; 0,10 - 0,15 $\mathrm{m}^{3}$ de $\mathrm{CH}_{4} \mathrm{~kg}^{-1}$ de cama de frango; $0,05 \mathrm{~m}^{3}$ de $\mathrm{CH}_{4} \mathrm{~kg}^{-1}$ de pena; $0,10 \mathrm{~m}^{3} \mathrm{de} \mathrm{CH}_{4} \mathrm{~kg}^{-1} \mathrm{de}$ sangue, e $0,30 \mathrm{~m}^{3}$ de $\mathrm{CH}_{4} \mathrm{~kg}^{-1}$ de vísceras, pés e cabeça.

Apesar de possuir um elevado potencial de produção de metano, as carcaças de aves são pouco utilizadas na produção de biogás, devido à dificuldade de manipulação e à necessidade de sistemas específicos de biodigestão anaeróbia (eliminação do excesso de gordura, proteína, ossos e penas), muito mais complexos e caros do que os sistemas comumente utilizados em propriedades rurais. Dessa forma, a compostagem (constituída de duas fases: pré-compostagem e compostagem propriamente dita) tem sido a principal forma de tratar esse tipo de resíduo. No entanto, apesar de ser considerado um excelente método, a compostagem de aves mortas apresenta um grande inconveniente em sua segunda fase (compostagem propriamente dita), que é o forte odor que o material possui durante sua manipulação. $\mathrm{O}$ odor deve-se à grande quantidade de gases que são eliminados durante a hidrólise do material, sendo a amônia o principal gás eliminado durante o processo (COSTA et al., 2006). Segundo os autores, a volatilização de amônia leva a quedas significativas nos teores de nitrogênio do composto final, diminuindo assim sua qualidade.

Uma forma de tentar resolver o problema de odor e das perdas de nitrogênio da segunda fase da compostagem, seria submeter o material pré-compostado ao processo de biodigestão anaeróbia, visto que as frações como ossos, penas e excesso de lipídios e proteína já foram previamente degradadas na primeira fase da compostagem, tornando o material passível de ser submetido à biodigestão em sistemas mais simples.

Diante do exposto, o objetivo do trabalho foi verificar a viabilidade técnica de se utilizar a biodigestão anaeróbia no tratamento dos resíduos cama de frangos e carcaças de aves pré-compostados, em substituição à segunda fase da compostagem.

\section{MATERIAL E MÉTODOS}

A pesquisa foi desenvolvida no Departamento de Engenharia Rural da Faculdade de Ciências Agrárias e Veterinárias da Universidade Estadual Paulista, Câmpus de Jaboticabal. Os resíduos utilizados, cama de frangos (cama proveniente de apenas um ciclo de produção) e carcaças de aves mortas, foram coletados em granja comercial na região de Ribeirão Preto. 
O período de pré-compostagem é uma fase que antecede à compostagem propriamente dita e é aplicada apenas quando se pretende compostar animais mortos. Essa fase é necessária para que ocorra uma decomposição prévia das aves, restando apenas partes de difícil degradação (bicos, ossos e penas, principalmente), facilitando assim o manejo do material, proporcionando melhor uniformidade e evitando sua exposição ao meio ambiente e a predadores. Essa fase foi realizada em uma composteira com paredes de blocos e piso de concreto, e dimensões de: 0,41 m de profundidade, $1,48 \mathrm{~m}$ de largura e $6,5 \mathrm{~m}$ de comprimento, com cobertura de lona plástica, sustentada por arcos semicirculares de ferro em toda a extensão, para evitar a entrada de água da chuva. A disposição dos resíduos na composteira foi em camadas alternadas de cama de frango e aves mortas, de forma que a primeira e a última camadas foram obrigatoriamente de cama de frangos. A proporção utilizada foi de três quilogramas de cama para cada quilograma de ave e adequando à umidade entre 40 e $60 \%$.

Após 60 dias de pré-compostagem, o material foi utilizado para o abastecimento de três biodigetores do tipo batelada de campo, que foram monitorados por um período de 14 semanas (enquanto mantiveram as produções de biogás). O modelo batelada foi escolhido, pois é um sistema mais adequado para o tratamento de resíduos que são removidos com menor frequência, ou seja, em sistemas onde a limpeza diária não é praticada (caso da avicultura). Os biodigestores batelada utilizados apresentam capacidade útil de 60 litros de substrato em fermentação e fazem parte de uma bateria de minibiodigestores, descrita por ORTOLANI et al. (1986) como demonstrado na Figura 1. O material resultante da pré-compostagem foi utilizado como substrato para os biodigestores, após diluição em água, procurando-se obter teor de sólidos totais inicial entre 6 e $8 \%$.

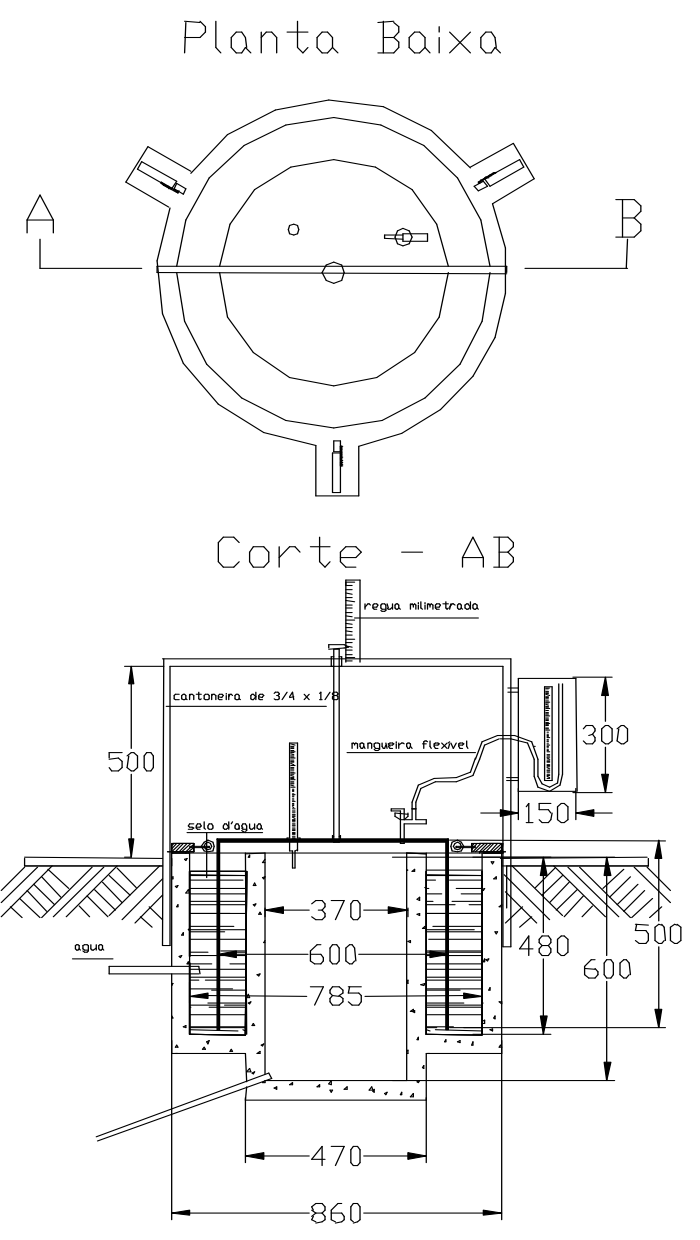

FIGURA 1. Esquema dos biodigestores batelada de campo, medidos em mm. (Fonte: ORTOLANI et al., 1986). Schedule of the batch field biodigestor, measured in mm. (Source: ORTOLANI et al., 1986). 
Os teores de sólidos totais (ST), sólidos voláteis e número mais provável (NMP) de coliformes totais e termotolerantes, das amostras coletadas durante o ensaio de biodigestão anaeróbia, foram determinados segundo metodologia descrita por APHA et al. (2005).

No momento do abastecimento dos biodigestores batelada, com os resíduos provenientes da avicultura de corte pré-compostados, observou-se teores de 52,10\% e 48,2\% de ST e SV, respectivamente. As quantidades dos componentes utilizados no preparo do substrato estão apresentados na Tabela 1.

TABELA 1. Quantidades dos componentes do substrato e teores de sólidos totais e voláteis no abastecimento de biodigestores batelada com os resíduos cama de frangos e carcaças de aves pré-compostados. Component quantities of substrate and levels of total solids and volatile in the supply of biodigestor with batch waste and chicken litter from poultry carcasses pre composted.

\begin{tabular}{lcccccc}
\hline & Substrato $(\mathrm{kg})$ & Água $(\mathrm{kg})$ & ST $(\%)$ & ST $(\mathrm{kg})$ & SV $(\%)$ & SV $(\mathrm{kg})$ \\
\hline Bio 1 & 7,4 & 52,6 & 6,43 & 3,86 & 5,92 & 3,55 \\
Bio 2 & 7,2 & 52,8 & 6,25 & 3,75 & 5,80 & 3,48 \\
Bio 3 & 8,3 & 51,7 & 7,20 & 4,32 & 6,66 & 4,00 \\
\hline
\end{tabular}

Os volumes de biogás produzidos diariamente foram determinados medindo-se o deslocamento vertical dos gasômetros e multiplicando-se pela área da seção transversal interna dos gasômetros, ou seja, $0,2827 \mathrm{~m}^{2}$. Após cada leitura, os gasômetros foram zerados, utilizando-se do registro de descarga do biogás.

Por se tratar de um experimento de campo, os reatores foram submetidos à variação da temperatura ambiental, por isso foi necessário o acompanhamento da temperatura interna dos reatores para posterior correção do volume de biogás. A correção do volume de biogás para as condições de $1 \mathrm{~atm}$ e $20{ }^{\circ} \mathrm{C}$ foi efetuada com base no trabalho de CAETANO (1985).

O potencial de produção de biogás foi calculado utilizando-se dos dados de produção total e das quantidades de material in natura, de substrato, de sólidos totais e de sólidos voláteis adicionados nos biodigestores, além das quantidades de sólidos voláteis reduzidos durante o processo de biodigestão anaeróbia. Os valores foram expressos em $\mathrm{m}^{3}$ de biogás $\mathrm{kg}^{-1}$ de substrato, de material ou de sólidos totais e voláteis.

As amostras coletadas durante o desenvolvimento dos ensaios de biodigestão foram pré-secadas a $60^{\circ} \mathrm{C}$, em estufa de circulação forçada de ar, por 48 horas. A seguir, foram finamente moídas, em moinho de facas, e então utilizadas para a digestão da matéria orgânica e determinação dos teores de sólidos voláteis.

Para a digestão, utilizou-se o digestor Digesdahl Hach, que promove a digestão total da matéria orgânica à base de ácido sulfúrico $\left(\mathrm{H}_{2} \mathrm{SO}_{4}\right)$ e peróxido de hidrogênio $\left(\mathrm{H}_{2} \mathrm{O}_{2}\right)$ a 50\% . Com este extrato, foi possível a determinação dos teores de $\mathrm{N}, \mathrm{P}, \mathrm{Ca}, \mathrm{Mg}, \mathrm{K}, \mathrm{Na}, \mathrm{Fe}, \mathrm{Zn}, \mathrm{Mn}$ e $\mathrm{Cu} . \mathrm{O}$ nitrogênio foi determinado conforme metodologia descrita por SILVA \& QUEIROZ (2006).

Os teores de fósforo foram determinados pelo método colorimétrico, utilizando-se de espectrofotômetro HACH, modelo DR-2000, como descrito por APHA et al. (2005). As concentrações de $\mathrm{Ca}, \mathrm{Mg}, \mathrm{K}, \mathrm{Na}, \mathrm{Fe}, \mathrm{Zn}, \mathrm{Mn}$ e $\mathrm{Cu}$ foram determinadas em espectrofotômetro de absorção atômica, modelo GBC 932 AA.

\section{RESULTADOS E DISCUSSÃO}

Os teores médios de sólidos totais (ST) e voláteis (SV), e a redução dos teores de sólidos voláteis, obtidos com a biodigestão dos resíduos de aves mortas e cama de frangos pré-compostados, estão apresentados na Tabela 2. 
TABELA 2. Teores médios iniciais e finais de sólidos totais (ST) e voláteis (SV) e redução de sólidos voláteis, para os biodigestores alimentados com os resíduos de aves mortas e cama de frangos pré-compostados. Average initial and final levels of total solids (TS) and volatile (VS), and reduction of volatile solids fed to the biodigestor waste and dead birds pre composted poultry litter.

\begin{tabular}{|c|c|c|c|c|c|c|c|c|c|}
\hline \multirow{3}{*}{ Reator } & \multicolumn{4}{|c|}{ ST } & \multicolumn{4}{|c|}{ SV } & \multirow{3}{*}{$\begin{array}{c}\text { Redução de SV } \\
(\%)\end{array}$} \\
\hline & \multicolumn{2}{|c|}{$\%$} & \multicolumn{2}{|c|}{$\mathrm{kg}$} & \multicolumn{2}{|c|}{$\%$} & \multicolumn{2}{|c|}{$\mathrm{kg}$} & \\
\hline & Af. & Ef. & Af. & Ef. & Af. & Ef. & Af. & Ef. & \\
\hline Bio 1 & 6,43 & 4,31 & 3,86 & 2,59 & 5,92 & 3,52 & 3,55 & 2,11 & 40,59 \\
\hline Bio 2 & 6,25 & 4,00 & 3,75 & 2,40 & 5,80 & 3,23 & 3,48 & 1,94 & 44,35 \\
\hline Bio 3 & 6,80 & 4,07 & 4,08 & 2,44 & 6,29 & 3,32 & 3,77 & 1,99 & 47,21 \\
\hline$\overline{\mathrm{DP}}$ & 0,28 & 0,16 & 0,17 & 0,10 & 0,26 & 0,15 & 0,15 & 0,09 & 2,66 \\
\hline
\end{tabular}

Af - afluente; Ef - efluente; DP - desvio-padrão

Observam-se reduções acentuadas nos teores de SV, em média 44,05\%, o que representa a eficiência da biodigestão anaeróbia na degradação de compostos resistentes, como a cama de frangos, visto que o material de fácil degradação, provavelmente, foi reduzido durante a pré-compostagem.

STEIL (2001) avaliou três níveis de inóculo na biodigestão anaeróbia da cama de frangos e observou que as porcentagens de redução de sólidos voláteis obtidas nas três condições foram de $53,45 \%$ sem inóculo adicional, 44,64\% e 42,00\% para as condições com 10 e $15 \%$ de inóculo, respectivamente.

SALMINEN \& RINTALA (2002) efetuaram a biodigestão anaeróbia dos resíduos de abatedouros das aves, utilizando biodigestores laboratoriais com capacidade de 3 litros e mantidos em temperatura constante $\left(31^{\circ} \mathrm{C}\right)$. Foram efetuadas cargas com diferentes concentrações de ST e diferentes tempos de retenção hidráulica e observadas reduções de SV de 63,0; 31,0; 74,0 e 76,0\%, quando utilizaram cargas com concentrações de 6,$2 ; 3,1 ; 4,7$ e 9,4\% de ST e períodos de retenção de $13 ; 25 ; 50$ e 100 dias, respectivamente.

As maiores reduções de SV encontradas pelos autores podem ser atribuídas à utilização de material fresco para o abastecimento dos biodigestores e manutenção dos reatores em temperatura de $31^{\circ} \mathrm{C}$, além do maior período de retenção (até 100 dias).

A distribuição da produção de biogás a partir dos resíduos aves mortas e cama de frangos pré-compostados está apresentada na Tabela 3. Nota-se que o total de biogás produzido foi menor que os encontrados por STEIL (2001) ao alimentar biodigestores com cama de frangos (totais de 1,37; 1,48 e 1,46 m³ de biogás em biodigestores de 60 litros e três condições de inoculação).

Tal fato pode estar associado ao período de pré-compostagem, no qual ocorreram significativas perdas de carbono e nitrogênio, reduzindo o potencial de produção de biogás em relação à cama original. Neste particular, ressalta-se a presença (mesmo em menor proporção) de materiais de degradação lenta e difícil, como ossos e penas. Apesar das menores produções de biogás, em comparação com a cama de frangos, foi observada a queima do biogás a partir do primeiro dia de produção, o que também pode ser atribuído à fase de pré-compostagem.

Os resultados dos potenciais de produção de biogás obtidos com a digestão anaeróbia dos resíduos aves mortas e cama de frangos pré-compostados, estão apresentados na Tabela 4. Os potenciais de produção de biogás obtidos podem ser considerados satisfatórios, principalmente ao se observar a composição dos substratos e a concentração de materiais de difícil degradação. Também deve ser considerada a redução de matéria orgânica durante a pré-compostagem, que poderia ter sido convertida em biogás. O potencial médio de $0,341 \mathrm{~m}^{3}$ de biogás $\mathrm{kg}^{-1} \mathrm{de}^{\mathrm{SV}}$ reduzido, reflete que houve eficiência na conversão de SV em biogás, apesar das produções de biogás observadas. 
TABELA 3. Produções $\left(\mathrm{m}^{3}\right)$ de biogás acumulada a partir dos resíduos aves mortas e cama de frangos pré-compostados. Production $\left(\mathrm{m}^{3}\right)$ of biogas accumulated waste from the litter of dead birds and chickens pre composted.

\begin{tabular}{cccc}
\hline Dias & Bio 1 & Bio 2 & Bio 3 \\
\hline 7 & 0,019519 & 0,012640 & 0,013179 \\
14 & 0,021293 & 0,013789 & 0,014378 \\
21 & 0,015289 & 0,033462 & 0,044705 \\
28 & 0,012206 & 0,052098 & 0,063971 \\
45 & 0,095747 & 0,170702 & 0,127498 \\
49 & 0,098804 & 0,092973 & 0,098790 \\
56 & 0,076318 & 0,030775 & 0,041538 \\
63 & 0,051034 & 0,050063 & 0,066401 \\
70 & 0,046885 & 0,057796 & 0,057765 \\
77 & 0,067407 & 0,046916 & 0,045946 \\
84 & 0,027289 & 0,012397 & 0,009130 \\
91 & 0,003581 & 0,006208 & 0,005957 \\
Total $\left(\mathrm{m}^{3}\right)$ & 0,003581 & 0,006208 & 0,005957 \\
\hline
\end{tabular}

TABELA 4. Potenciais de produção de biogás em $\mathrm{m}^{3} \mathrm{~kg}^{-1}$ de $\mathrm{ST}$ adicionados, SV adicionados, substrato, material e SV reduzidos nos biodigestores alimentados com os resíduos aves mortas e cama de frangos pré-compostados. Potential production of biogas in $\mathrm{m}^{3} \cdot \mathrm{kg}^{-1}$ of TS added, VS added, substrate material and reduced VS biodigestor fed the waste bed of dead birds and chickens pre-composted.

\begin{tabular}{llll}
\hline Potenciais de produção & Bio 1 & Bio 2 & Bio 3 \\
\hline $\mathrm{m}^{3} \mathrm{~kg}^{-1}$ de ST adicionado & 0,135 & 0,153 & 0,135 \\
$\mathrm{~m}^{3} \mathrm{~kg}^{-1}$ de SV adicionado & 0,146 & 0,165 & 0,146 \\
$\mathrm{~m}^{3} \mathrm{~kg}^{-1}$ de substrato & 0,009 & 0,010 & 0,010 \\
$\mathrm{~m}^{3} \mathrm{~kg}^{-1}$ de material & 0,070 & 0,080 & 0,070 \\
$\mathrm{~m}^{3} \mathrm{~kg}^{-1}$ de SV reduzido & 0,360 & 0,372 & 0,291 \\
\hline
\end{tabular}

STEIL (2001) obteve resultados superiores quando efetuou a biodigestão da cama de frangos: $0,0246 \mathrm{~m}^{3}$ de biogás por $\mathrm{kg}$ de substrato e $0,2328 \mathrm{~m}^{3}$ de biogás por $\mathrm{kg}$ de resíduo quando utilizou $10 \%$ de inóculo, $0,0243 \mathrm{~m}^{3}$ de biogás por $\mathrm{kg}$ de substrato e $0,2433 \mathrm{~m}^{3}$ de biogás por $\mathrm{kg}$ de resíduo ao utilizar $15 \%$ de inóculo e $0,0229 \mathrm{~m}^{3}$ de biogás por $\mathrm{kg}$ de substrato e $0,1953 \mathrm{~m}^{3}$ de biogás por $\mathrm{kg}$ de resíduo. Tais diferenças podem ser atribuídas ao uso de inóculo, às diferentes composições dos substratos, já que as carcaças de aves pré-compostadas podem ter reduzido a eficiência de produção de biogás por quantidade de material adicionado aos biodigestores e, finalmente, pelo maior período de operação dos biodigestores, que foi de 133 dias, enquanto neste trabalho foi de apenas 98 dias.

Os resultados médios dos exames microbiológicos dos afluentes e efluentes dos biodigestores são apresentados na Tabela 5. Comparando-se o NMP médio dos afluentes e efluentes dos biodigestores batelada de campo, observa-se que a digestão anaeróbia promoveu acentuada redução dos coliformes totais e termotolerantes, com valores acima de $99 \%$ para ambos.

Resultados semelhantes foram encontrados por COTÉ et al. (2006) que observaram eficiência de 97,94 a $100 \%$ nas reduções de coliformes termotolerantes e totais em sistemas de biodigestão anaeróbia, mesmo quando esses foram submetidos à condição de baixa temperatura $\left(20^{\circ} \mathrm{C}\right)$. Segundo os mesmos autores, a eficiência na redução dos microrganismos patogênicos está associada à temperatura de fermentação e ao TRH utilizado, sendo que, quanto maiores forem os seus valores, mais eficiente será a redução de patógenos. Na literatura, existem vários autores, entre 
os quais AMORIM et al. (2004), MENTZ et al. (2004) e AMARAL et al. (2004), que comprovaram a eficiência do processo de biodigestão anaeróbia, na redução de diversas espécies de organismos patogênicos.

TABELA 5. Número mais provável de coliformes totais e termotolerantes (por grama de material) no afluente e efluente de biodigestores alimentados com os resíduos aves mortas e cama de frangos pré-compostados. Most probable number of total and thermotolerant coliforms (per gram of material) in the affluent and effluent of biodigestor fed with dead birds and poultry litter pre composted.

\begin{tabular}{ccccccc}
\hline \multirow{2}{*}{ Biodigestor } & \multicolumn{5}{c}{ NMP g $^{-1}$ de Material } \\
\cline { 2 - 7 } & \multicolumn{5}{c}{ Coliformes Totais } & \multicolumn{2}{c}{ Coliformes Termotolerantes } \\
\hline & Início & Final & Redução (\%) & Início & Final & Redução (\%) \\
2 & $3,610^{5}$ & $1,110^{3}$ & 99,7 & $7,310^{3}$ & $1,110^{2}$ & 98,5 \\
3 & $3,910^{5}$ & $1,110^{3}$ & 99,7 & $7,310^{3}$ & $1,110^{2}$ & 98,5 \\
\hline Média & $3,610^{5}$ & $3,610^{1}$ & 100,0 & $7,310^{3}$ & 0,0 & 100,0 \\
\hline
\end{tabular}

Apesar da grande redução observada no NMP de coliformes, ainda não foi suficiente para a utilização do efluente para alguns fins. De acordo com a resolução CONAMA 357 (2005), esse efluente não pode ser utilizado para irrigação de hortaliças e plantas frutíferas, pois as quantidades de coliformes não são inferiores a $10^{2} / 100 \mathrm{~mL}$ de biofertilizante.

Na Tabela 6, estão apresentados os resultados referentes à caracterização do afluente e efluente dos biodigestores abastecidos, com os resíduos cama de frangos e carcaças pré-compostados. Os valores apresentados na Tabela 6 refletem a importância do processo de biodigestão anaeróbia, no que se refere à concentração dos nutrientes no efluente, quando comparados com o afluente. Esse aumento se deve à redução de ST que foi convertido em biogás, ocasionando assim a concentração da fração mineral.

TABELA 6. Teores de P, K, Mg, Ca e Na (g/100 g de matéria seca), Fe, Mn, Cu e Zn (mg/100 g de matéria seca) no afluente e efluente dos biodigestores abastecidos com os resíduos da avicultura de corte pré-compostados. Levels of $\mathrm{P}, \mathrm{K}, \mathrm{Mg}, \mathrm{Ca}$ and $\mathrm{Na}$ (g/100 g dry matter), Fe, Mn, $\mathrm{Cu}$ and $\mathrm{Zn}$ (mg/100g dry matter) in the influent and effluent of biodigestor supplied with the waste of pre-cut poultry-composted.

\begin{tabular}{lcccccccccc}
\hline \multirow{2}{*}{ Identificação } & $\mathrm{P}$ & $\mathrm{N}$ & $\mathrm{Ca}$ & $\mathrm{Mg}$ & $\mathrm{K}$ & $\mathrm{Na}$ & $\mathrm{Fe}$ & $\mathrm{Mn}$ & $\mathrm{Cu}$ & $\mathrm{Zn}$ \\
\cline { 2 - 12 } & \multicolumn{9}{c}{$\mathrm{g} / 100 \mathrm{~g} \mathrm{ST}$} \\
Af. bio 1 & 2,19 & 2,11 & 0,83 & 0,48 & 3,10 & 0,88 & 88,37 & 31,16 & 15,48 & 15,21 \\
Af. bio 2 & 1,90 & 1,90 & 0,75 & 0,43 & 2,85 & 0,82 & 84,79 & 28,95 & 13,55 & 12,86 \\
Af. bio 3 & 1,99 & 1,83 & 0,72 & 0,40 & 2,76 & 0,76 & 82,31 & 27,63 & 13,81 & 12,31 \\
\hline Ef. bio 1 & 1,23 & 2,41 & 7,99 & 4,44 & 18,33 & 2,15 & 127,16 & 39,32 & 23,06 & 25,06 \\
Ef. bio 2 & 1,26 & 2,18 & 7,99 & 5,36 & 18,33 & 2,28 & 124,52 & 38,44 & 21,42 & 24,36 \\
Ef. bio 3 & 1,34 & 2,27 & 8,02 & 4,43 & 18,33 & 2,21 & 121,78 & 38,52 & 21,42 & 25,92 \\
\hline
\end{tabular}

Af - afluente; Ef - efluente

Os incrementos esperados nas concentrações dos elementos deveriam ser proporcionais à redução de massa seca, pois, durante a fermentação, grande parte da matéria orgânica é convertida, principalmente, em metano e dióxido de carbono, ocasionando assim a concentração da matéria mineral. No entanto, foram observados aumentos, muito acima dos previstos, nos teores de $\mathrm{Ca}, \mathrm{Na} e$ $\mathrm{Fe}$, no efluente, quando comparado com o afluente. Esse fato pode estar relacionado com a heterogeneidade do material inicial, o qual ainda possuía partículas grandes de ossos e penas (ainda não degradados), subestimando assim os teores desses nutrientes na análise do afluente. Já no efluente, não foram observadas a presença dessas partículas, ou seja, essas partículas foram 
degradadas, e os nutrientes contidos nas mesmas foram liberados, aumentando significativamente seus teores no efluente.

\section{CONCLUSÕES}

A biodigestão anaeróbia dos resíduos cama de frangos e carcaças de aves pré-compostadas não demonstrou grande eficiência do ponto de vista de produção de gás, sendo encontrado reduzido potencial de produção, o que, em condições práticas, inviabilizaria o emprego do processo. Em contrapartida, sua utilização foi positiva quanto aos seguintes aspectos: conservação dos nutrientes contidos no resíduo, reduzida emissão de odores e redução de coliformes.

\section{REFERÊNCIAS}

ALVAREZ, R.; VILLCA, S.; LIDÉN, G. Biogas production from llama and cow manure at high altitude. Biomass and Bioenergy, Aberdeen, v.30, n.3, p.66-75, 2006.

AMARAL, C.M.C.; AMARAL, L.A.; LUCAS JÚNIOR, J.; NASCIMENTO, A.A.; FERREIRA, D.S.; MACHADO, M.R.F. Biodigestão anaeróbia de dejetos de bovinos leiteiros submetidos a diferentes tempos de retenção hidráulica. Ciência Rural, Santa Maria, v.34, n.6, p.1.897-1.902, 2004.

AMERICAN PUBLIC HEALTH ASSOCIATION; AMERICAN WATER WORKS ASSOCIATION; WATER ENVIRONMENT FEDERATION (APHA; AWWA, WEF). Standard methods for examination of water and wastewater. $21^{\text {th }}$ ed. Washington: American Water Works Association, 2005. $1.368 \mathrm{p}$.

AMORIM, A.C.; LUCAS JÚNIOR, J.; RESENDE, K.T. Biodigestão anaeróbia de dejetos de caprinos obtidos nas diferentes estações do ano. Engenharia Agrícola, Jaboticabal, v.24, n.1, p.1624, 2004.

ANGONESE, A.R.; CAMPOS, A.T.; ZACARKIM, C.E.; MELISSA S.; MATSUO, M.S.; CUNHA, F. Eficiência energética de sistema de produção de suínos com tratamento dos resíduos em biodigestor. Revista Brasileira de Engenharia Agrícola e Ambiental, Campina Grande, v.10, n.3, p.745-750, 2006.

ANUALPEC 2007: anuário estatístico da pecuária brasileira. São Paulo: FNP Consultoria e Comércio, 2004. 392 p.

CAETANO, L. Proposição de um sistema modificado para quantificação de biogás. $1985.75 \mathrm{f}$. Dissertação (Mestrado em Energia na Agricultura) - Faculdade de Ciências Agronômicas, Universidade Estadual Paulista, Botucatu, 1985.

CONAMA. CONSELHO NACIONAL DO MEIO AMBIENTE. Padrões de qualidade para os parâmetros monitorados na rede de monitormento, segundo Resolução CONAMA 357/2005. Disponível em: <http://www.mma.gov.br/port/conama/res/res05/>. Acesso em: $11 \mathrm{dez} .2007$.

COSTA, M.S.S.M.; COSTA, L.A.M.; SILVA, A.C.J.; DECARLI, L.D.; MATTER, U.F. Desempenho de quatro sistemas para compostagem de carcaça de aves. Revista Brasileira de Engenharia Agrícola e Ambiental, Campina Grande, v.10, n.3, p.692-698, 2006.

CÔTE, C.; MASSE, D.I.; QUESSY, S. Reduction of indicator and pathogenic microorganisms by psychrophilic anaerobic digestion in swine slurries. Bioresource Technology, Oxford, v.97, n.1, p.686-691, 2006.

DEMIRER, G.N.; CHEN, S. Two-phase anaerobic digestion of unscreened dairy manure. Process Biochemistry, Irlanda, v.40, n.4, p.3.542-3.549, 2005.

GÜNGÖR-DEMIRCI, G.; DEMIRER, G. N. Effect of initial COD concentration, nutrient addition, temperature and microbial acclimation on anaerobic treatability of broiler and cattle manure.

Bioresource Technology, Oxford, v.93, n.2, p.109-117, 2004. 
MENTZ, M.B.; WIEST, J.M.; GONÇALVES, P.C. Viabilidade de ovos de Fasciola hepatica de bovinos em sistema de biodigestão anaeróbia. Arquivos Brasileiros Medicina Veterinária e Zootecnia, Belo Horizonte, v.56, n.4, p.550-553, 2004.

ORRICO, A.C.A.; LUCAS JÚNIOR, J.; ORRICO JÚNIOR, M.A.P. Caracterização e biodigestão anaeróbia dos dejetos de caprinos. Engenharia Agrícola, Jaboticabal, v.27, n.3, p.639-647, 2007.

ORTOLANI, A.F.; LUCAS JÚNIOR, J.; GALBIATTI, J.A.; LOPES, L.R.; ARAÚJO, J.A.C.; BENINCASA, M.; BEDUSCHI, L.C.; COAN, O.; PAVANI, L.C.; MILANI, A.P.; DANIEL, L.A.; LATANZE, R.J. Bateria de minibiodigestores: estudo, projeto, construção e desempenho. In: CONGRESSO BRASILEIRO DE ENGENHARIA AGRÍCOLA, 15., 1986, São Paulo. Anais... Botucatu: FCA/UNESP, 1986. p.229-239.

SALMINEN, E.A.; RINTALA, J.A. Semi-continous anaerobic digestion of solid poultry slanghterhouse waste: effect of hydraulic retention time and loading. Water Research, Londres, v.36, p.3.175-3.182, 2002.

SANTOS, T.M.B.; LUCAS JÚNIOR, J.; SILVA, F.M. Avaliação do desempenho de um aquecedor para aves adaptado para utilizar biogás como combustível. Engenharia Agrícola, Jaboticabal, v.27, n.3, p.658-664, 2007.

SILVA, D.J.; QUEIROZ, A.C. Análise de alimentos: métodos químicos e biológicos. 3.ed.Viçosa MG: Editora Universitária, 2006. 166 p.

SILVA, F.M.; LUCAS JÚNIOR, J.; BENINCASA, M.; OLIVEIRA, E. Desempenho de um aquecedor de água a biogás. Engenharia Agrícola, Jaboticabal, v.25, n.3, p.608-614, 2005.

STEIL, L. Avaliação do uso de inóculos na biodigestão anaeróbia de resíduos de aves de postura, frangos de corte e suínos. 2001. 109 f. Dissertação (Mestrado em Biotecnologia) - Instituto de Química, Universidade Estadual Paulista, Araraquara, 2001. 